\title{
Rammya Mathew: The pursuit of being a good doctor
}

\author{
Rammya Mathew GP \\ London
}

The aspiration to be a good doctor is probably common to us all, but what does it really mean? Has anyone defined "good?" I'm reminded of many personal statements I've read over the years in which students, vying for a highly sought after place in medical school, claim to be cut out for the job because they're empathetic or willing to go the extra mile to help others.

Empathy is an ambiguous concept, but in medicine it can be loosely defined as an emotional experience between clinician and patient, where the clinician identifies with and transiently experiences the patient's emotional state. ${ }^{1}$ Importantly, it's thought to increase one's motivation to help others, so it's no surprise that empathy and altruism tend to go hand in hand. ${ }^{2}$

Empathy is also a trait highly valued by patients, yet evidence indicates that doctors often lack $\mathrm{it}^{3}$ and that it declines throughout our medical training. ${ }^{45}$ Is there something wrong with the way we train doctors, or is it normal for our empathy to decrease with repeated and sustained exposure to emotions such as grief, pain, suffering, and fear-which we encounter almost every day through our interactions with patients?

In my own consultations I'm aware that I sometimes forget the clock and give patients the time they need because it feels like the right thing to do, but admittedly I've sometimes brushed aside cues, knowingly or unknowingly, that should have been greeted with empathy_-perhaps because I was tired, stressed, running late, or simply unable to give any more that day. Does that make me an unempathetic or bad doctor?

As healthcare professionals, it feels as though we do very little to cultivate our empathy or to prevent it from being eroded by the various environmental stressors we face. I wonder whether the emergence of mindfulness in new medical school curriculums will better equip prospective doctors to maintain their empathy levels in a high pressure, emotionally charged working environment.

We'll never get it perfect all of the time, but it feels as though we should be giving as much of ourselves as we can, so that we feel fulfilled in our jobs and our patients feel cared for-but not so much that we become burnt out and emotionally depleted. This is important for our own wellbeing but is also central to our vocation, which is about alleviating suffering, not just curing disease.

Arguably, Edward Livingston Trudeau's philosophy, "to cure sometimes, to relieve often, to comfort always," may be overly idealistic — but it does bring home the need to understand and nurture our capacity for empathy, when pursuing our aspiration to be "good" doctors.

Competing interests: I have read and understood BMJ policy on declaration of interests and declare that I have no competing interests.

Provenance and peer review: Commissioned; not externally peer reviewed.

1 Hirsch EM. The role of empathy in medicine: a medical student's perspective. Virtual Mentor 2007;9:423-7. 10.1001/virtualmentor.2007.9.6.medu1-0706. 23218048

2 Pavey L, Greitemeyer T, Sparks P. "I help because I want to, not because you tell me to": empathy increases autonomously motivated helping. Pers Soc Psychol Bull 2012;38:681-9. 10.1177/0146167211435940. https://journals.sagepub.com/doi/abs/10. $1177 / 0146167211435940.22326945$

3 Jeffrey D. Clarifying empathy: the first step to more humane clinical care. Br J Gen Pract 2016;66:e143-5. 10.3399/bjgp16X683761. https://bjgp.org/content/66/643/e143. 26823264

4 Hojat M, Mangione S, Nasca TJ, etal . An empirical study of decline in empathy in medical school. Med Educ 2004:38:934-41. https://www.ncbi.nlm.nih.gov/pubmed/15327674. 10.1111/j.1365-2929.2004.01911.x 15327674

5 Chen DC, Kirshenbaum DS, Yan J, Kirshenbaum E, Aseltine RH. Characterizing changes in student empathy throughout medical school. Med Teach 2012;34:305-11. 10.3109/0142159X.2012.644600. https://www.ncbi.nlm.nih.gov/pubmed/ 22455699. 22455699

Published by the BMJ Publishing Group Limited. For permission to use (where not already granted under a licence) please go to http://group.bmj.com/group/rights-licensing/ permissions 